\title{
Sentido y comunidad. La dimensión política del sentido común en Deleuze
}

\section{Sense and Community. The Political Dimension of Common Sense in Deleuze}

\author{
PABLO NICOLÁS PACHILLA \\ Universidad de Buenos Aires, CONICET
}

Recibido: 01/04/2018 Aceptado:10/07/2018

\begin{abstract}
RESUMEN
En el presente artículo se procurará subrayar la dimensión política del concepto de sentido común en la filosofía de Gilles Deleuze, señalando algunas transformaciones al respecto desde Diferencia y repetición (1968) hasta sus textos de los años '80. Mostraremos que el sentido común implica una presencia implícita de la comunidad en el ejercicio de las facultades, que sin embargo invisibiliza y despolitiza su propia presencia, y rastrearemos la letra kantiana para señalar que la comunidad implícita en el sensus communis se revela como una comunidad «mayoritaria» relativa a un modelo que no se corresponde con los devenires efectivos.
\end{abstract}

\section{PALABRAS CLAVE \\ DELEUZE, KANT, SENTIDO COMÚN, SENSUS COMMUNIS}

\begin{abstract}
The aim of this paper is to underline the political dimension of the concept of common sense in Gilles Deleuze's philosophy, pointing out its transformations from Difference and Repetition (1968) to his texts from the ' 80 s. We will show that common sense implies an implicit presence of the community in the exercise of the faculties, and track its Kantian roots in order to reveal the community implicit in the sensus communis as a «majoritarian» community, relative to a model unlike the real becomings.
\end{abstract}

\author{
KEYWORDS \\ DELEUZE, KANT, COMMON SENSE, SENSUS COMMUNIS
}
(C) Contrastes. Revista Internacional de Filosofía, vol. XXIV-No ${ }^{\circ}$ (2019), pp. 41-58. ISSN: 1136-4076 Departamento de Filosofía, Universidad de Málaga, Facultad de Filosofía y Letras Campus de Teatinos, E-29071 Málaga (España)


La historia entera de la filosofía, que nos dice tanto sobre los objetos del pensamiento y tan poco sobre el proceso del pensar mismo, está atravesada por una lucha interna entre el sentido común del hombre, este altísimo, sexto sentido que adapta nuestros cinco sentidos a un mundo común y nos permite orientarnos en él, y la facultad de pensar, en virtud de la cual el hombre se aleja deliberadamente de él. ${ }^{1}$

Hannah Arendt (1971, pp. 424-425)

EN UN CONTEXTO COMO el actual, en el que proliferan los call-centers contratados por grupos políticos para retwittear, likear y trollear, es decir, para influir en el sentido común, se vuelve imperioso tomar una distancia crítica de este último y preguntarse filosóficamente por el mismo. ¿Cuál es la naturaleza del sentido común? ¿Cuáles son las implicancias de guiarse por él? Estas son las preguntas que nos ocuparán en el presente trabajo, y en vista de las cuales tomaremos las críticas deleuzianas al concepto de sentido común, señalando al mismo tiempo algunas transformaciones al respecto desde su primer gran obra «en nombre propio» hasta el colosal trabajo de madurez junto a Félix Guattari y sus estudios sobre cine. Para ello será necesario asimismo un análisis de la noción kantiana de sensus communis, en tanto que la misma inaugura la versión moderna del concepto en cuestión y explicita, siempre que se la lea atentamente, los supuestos criticados por Deleuze.

\section{SENTIDO COMÚN COMO LUGAR COMÚN}

En el tercer capítulo de Diferencia y repetición (1968), intitulado «La imagen del pensamiento», Gilles Deleuze lleva a cabo una crítica radical de los presupuestos subjetivos en lo que concierne a lo que significa pensar y ser. Según el filósofo, Descartes habría inaugurado una tradición consistente en tomar un punto de partida del filosofar que dejaría de lado supuestos objetivos - los cuales caerían bajo la duda metódica - pero no por ello evadiría ciertos presupuestos subjetivos. Deleuze despliega de este modo ocho postulados,

1 Todas las traducciones al castellano de textos en otros idiomas son de nuestra autoría, salvo que se indique lo contrario. 
que considera constituyen la «imagen dogmática»o «moral» del pensamiento. En estrecha relación con esta imagen del pensamiento se encuentra el sentido común, que adopta no obstante significados diversos. En primer lugar, el sentido común se identifica con la imagen del pensamiento misma, en tanto ella da por sentadas la buena naturaleza del pensador y la naturaleza recta del pensamiento. En segundo lugar, el sentido común concierne a la concordia entre las facultades, esto es, consiste en un determinado modo de ejercicio de las facultades subjetivas según el cual cada una no aprehenderá de su objeto propio sino aquello que puede ser relacionado armónicamente con el objeto de todas las otras facultades, y en última instancia remitido a un objeto reconocido como correlato del pensamiento. En tercer lugar, el sentido común adopta un cariz más específico en cuanto se lo piensa como correlativo al buen sentido: mientras que el primero aporta la forma del objeto cualquiera, el segundo reparte el aporte de cada facultad, es decir, cualifica el objeto.

Ahora bien, los tres sentidos mencionados se funden aun con el significado que el propio sentido común se da a sí mismo: lo que «uno» piensa, que abarca tanto una serie de presuntas habilidades o tendencias a darse cuenta de ciertas cosas (forma) como una serie de elementos concretos que plenifican esas tendencias, a saber, aquello de lo que uno se da cuenta ( $\varphi v ́ \sigma \varepsilon 1$, por lumière naturelle, etc.). Estos no son sino los lugares comunes, que se pueden expresar de distintas maneras, desde los refranes de la asíllamada sabiduría popular hasta las verdades autoevidentes de la filosofía clásica. ${ }^{2}$ Un ejemplo paradigmático en este último sentido es para Deleuze el de la dialéctica aristotélica: por un lado, reviste un potencial para hacerse cargo de los problemas y no sólo de las soluciones (y por ello salirse de la imagen ortodoxa del pensamiento), pero por el otro, dice Aristóteles que hay que partir de ह̌v $\delta$ o $\xi \alpha$, opiniones probables o cosas plausibles «que parecen bien a todos, o a la mayoría, o a los sabios, y entre estos últimos, a todos, o a la mayoría, o a los más conocidos y reputados.» (Aristóteles, 1982, p. 90, Tópicos, 100b) El movimiento hacia fuera de la doxa, dado por la potencia de hacerse cargo de los problemas y no sólo de las soluciones, recae de ese modo en la doxa sostenida por la apelación a la autoridad.

Los lugares comunes serán asimismo un tema de exploración para Deleuze en sus estudios sobre cine. La crisis de la imagen-acción analizada

2 En este sentido, Barthes habla de una transición semántica operada entre Aristóteles y los sofistas pos-aristotélicos con respecto a los lugares comunes: mientras que en un primer momento mentaban meras formas, el término adoptó luego el sentido de estereotipos. «Los lugares son, en principio, formas vacías; pero estas formas mostraron muy pronto una tendencia a llenarse siempre de la misma manera, a apoderarse de contenidos primero contingentes, luego repetidos, reificados.» (Barthes, 1982, p. 57). 
sobre el final de La imagen-movimiento implica que los nexos entre estímulo y reacción se han debilitado; los personajes ya no encuentran orientación ni centro en su medio circundante, que ya no se puede llamar propiamente «mundo». Lo que mantiene unido como conjunto esa dispersión sin totalidad ni encadenamiento sensorio-motor son los clichés. En esa realidad «dispersiva y lacunaria» en la que los personajes deambulan sin rumbo fijo y sin sentir los acontecimientos en carne propia, los clichés, eslóganes sonoros y visuales pero también psíquicos, cimentan los pedazos otorgando una unidad precaria.

Son esas imágenes flotantes, esos clichés anónimos, que circulan en el mundo exterior, pero también que penetran a cada uno y constituyen su mundo interior, de modo que cada uno no posee en sí sino clichés psíquicos por los cuales piensa y siente, se piensa y se siente, siendo él mismo un cliché entre los otros en el mundo que lo rodea. Clichés físicos, ópticos y sonoros, y clichés psíquicos se alimentan mutuamente. Para que la gente se soporte, a ellos mismos y al mundo, es necesario que la miseria haya ganado el interior de las conciencias, y que el adentro sea como el afuera. (Deleuze, 1983, p. 281)

En efecto, una «organización del Poder» ha encontrado la manera de hacer circular los clichés de afuera hacia adentro y viceversa. Los lugares comunes sensibles y mentales que mantienen unidos los escombros de lo que otrora fuera la subjetividad tienen, en este contexto de pobreza de mundo, una relación intrínseca con un poder que los hace circular en aras de mantener ese estado de cosas. Sin embargo, los clichés también pueden convertirse en el límite que nos hace pasar a otro registro cuando ya no podemos soportarlos. Ordinariamente sólo percibimos clichés, entendidos bergsonianamente como el escorzo de las cosas que «nos interesa», en la medida en que nuestro esquema sensorio-motor mantiene aún un débil interés.

Pero, si nuestros esquemas sensorio-motores se bloquean o se rompen, entonces puede aparecer otro tipo de imagen: una imagen óptica-sonora pura, la imagen entera sin metáfora, que hace surgir la cosa en sí misma, literalmente, en su exceso de horror o de belleza, en su carácter radical o injustificable, puesto que ya no tiene que ser «justificada», para bien o para mal... (Deleuze, 1985, p. 32)

Es, paradigmáticamente, el caso de los personajes de los films de posguerra de Rossellini, que ven o sienten algo demasiado intenso y que ya no pueden soportar: Edmund en Germania anno zero (1948) y los personajes interpretados por Ingrid Bergman en Stromboli (1950) y Europa '51 (1952). ${ }^{3}$

3 «Estoy acabada, tengo miedo, qué misterio, qué belleza, Dios mío...» dice la migrante lituana Karin frente a la «potencia pánica» de la erupción del volcán en la isla de Stromboli. 
Como dice Flaubert de Bouvard y Pécuchet, una facultad se desarrolló en sus espíritus: la de ver la bêtise y ya no tolerarla. ${ }^{4}$

En La imagen-movimiento y La imagen-tiempo, entonces, los clichés son las imágenes-cosas que conforman nuestros vínculos pobres con el medio, puestos en circulación por un tipo de organización de poder que desea perpetuar la miseria; son aquello que nos mantiene en la impasible rutina de una cotidianeidad vaciada. Pero, por esa misma razón, yace en ellos una potencialidad inminente: al quebrarse nuestros débiles nexos corporales y psíquicos con los clichés, un nuevo régimen de visibilidad puede hacer irrupción-lo que Deleuze llama situaciones ópticas y sonoras puras. Como escribiera Hölderlin, donde impera el peligro, crece también lo que nos salva («Wo aber Gefahr ist, wächst das Rettende auch») (Hölderlin, 1953, p. 172). Lo mismo sucede con el sentido común como concordia facultatum: si somete los flujos a una organización empobrecedora, deshacerse de su yugo abre los flujos a la potencia de una vida inaudita. Este será el rol de lo sublime, experiencia en la cual, como dice Deleuze, «lo intolerable mismo no es separable de una revelación o de una iluminación.» (Deleuze, 1985, p. 29) En este sentido, la función de videncia que adoptan los personajes de Rossellini recupera, según Deleuze, el espíritu romántico. «El romanticismo se proponía ya este objetivo: aprehender lo intolerable o lo insoportable, el imperio de la miseria y, con ello, devenir visionario, hacer de la visión pura un medio de conocimiento y de acción.» (Ibid.)

El concepto deleuziano de sentido común es complejo y abarca distintos aspectos. Resulta especialmente interesante el hecho de que Deleuze funda en un mismo concepto el sentido técnico de una determinada relación concordante entre las facultades con un sentido más general relativo a los lugares comunes, los clichés, tó una perspectiva noético-discursiva en Diferencia y repetición hasta el punto de vista de una semiótica materialista en La imagen-movimiento y La imagentiempo; desde lo que la mayoría o los sabios piensan o lo que nadie puede negar hasta los eslóganes que carcomen el alma urbana posfordista en los

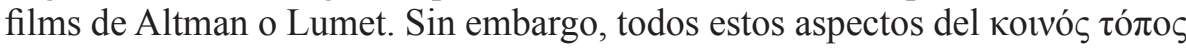
revisten un elemento insoslayable: ponen en juego, de distintas maneras, una comunidad. Es con los lugares comunes aceptados por nuestra comunidad que nuestros razonamientos deben concordar, o de los cuales deben partir.

4 El término bêtise constituye un término técnico de la filosofía deleuziana difícil de traducir. Algunas traducciones posibles del mismo son: estupidez, necedad, ignominia, burrada. Al respecto, $c f$. Ferreyra, 2016, pp. 26-36. 


\section{SENTIDO COMÚN COMO SENTIDO COMUNITARIO}

La objetividad requiere, tanto de hecho como de derecho, una comunidad de sentido: concordancia de las facultades - identidad subjetiva - que hace converger los flujos en el punto ideal hacia al cual se dirigen -identidad objetiva - ${ }^{5}$ A hora bien, esa comunidad de sentido en tanto sentido compartido es al mismo tiempo un sentido comunitario, toda vez que la concordancia debe ser capaz de cumplir con la pretensión de universalidad: «el reconocimiento reclama entonces un principio subjetivo de la colaboración de las facultades para 'todo el mundo', es decir, un sentido común como concordia facultatum.» (Deleuze, 1968, p. 174) Este «todo el mundo» no es otra cosa que la presencia implícita de una comunidad en el ejercicio de las facultades. Podemos encontrar la expresión "sentido comunitario» en la Crítica de la facultad de juzgar de Kant, donde es identificada con el sensus communis:

Pero por sensus communis ha de entenderse la idea de un sentido comunitario [gemeinschaftlichen Sinnes], es decir, de una facultad de juzgar que, en su reflexión, tiene en cuenta por el pensamiento (a priori) el modo de representación de los demás para atener su juicio, en cierto modo, a la razón total humana [die gesamte Menschenvernunft], y así evitar la ilusión que, nacida de condiciones privadas subjetivas, fácilmente tomadas por objetivas, tendría una influencia perjudicial en el juicio. (AA V, 293)

Por eso, como sostiene Hannah Arendt en su curso sobre la filosofía política kantiana, «cuando uno juzga, lo hace como miembro de una comunidad.» (Arendt, 1992, p. 72) La autora subraya asimismo que «sentido común [common sense] es sentido comunitario [community sense], sensus communis, en tanto distinto del sensus privatus. Este sensus communis es aquello a lo que el juicio apela en todos, y es esta apelación posible lo que le da a los juicios su validez especial.» (Ibid.) Ahora bien, en la nota al pie con la que finaliza la Observación a la «Deducción de los juicios de gusto» de la tercera Crítica,

5 Se trata de lo que Henry Allison ha denominado la «tesis de la reciprocidad» a propósito de Kant. $C f$. Allison, 1992, p. 235.

6 Oyarzún y García Morente traducen gemeinschaftlich por «común a todos» y «que es común a todos», respectivamente. Sin embargo, puesto que Gemeinschaft significa «comunidad», la traducción más literal nos parece al mismo tiempo la más adecuada en ese contexto. $C f$. Kant, 1991, p. 204, Kant, 2007, p. 234. Para la obra de Kant, utilizamos la abreviatura establecida por la Academia de Ciencias de Berlín: AA por Akademieausgabe, seguido del volumen en números romanos, la página en números arábigos y las líneas luego de un punto, en caso de ser necesario. A continuación, indicamos entre paréntesis para la facilidad del lector las traducciones al castellano (que seguimos parcialmente) de Pablo Oyarzún y de Manuel García Morente de la Kritik der Urteilskraft con las abreviaturas CFJ y CJ, respectivamente. 
Kant nos pide que aceptemos, «[p]ara tener derecho [um berechtig zu sein] a la pretensión [Anspruch] de aprobación [Beistimmung] universal respecto de un juicio de la facultad de juzgar estética que descanse sólo en fundamentos subjetivos», que las condiciones subjetivas de la facultad de juzgar en lo que respecta al conocimiento son las mismas en todos los hombres, «porque de otro modo los hombres no se podrían comunicar sus representaciones ni incluso el conocimiento.» (AA V, 290.n; CFJ 201, CJ 230) Nuevamente asoma allí otro presupuesto, a saber, que esta comunidad es homogénea.

La necesidad del sentido común en tanto sentimiento de la comunidad implícita al juicio aparece con toda su fuerza en el $\$ 20$ de la Crítica de la facultad de juzgar. En ese parágrafo, intitulado «La condición de la necesidad a la que aspira un juicio de gusto es la idea de un sentido común [Gemeinsinn]», Kant escribe:

Si los juicios de gusto (al igual que los juicios de conocimiento) tuviesen un principio objetivo determinado, quien los emitiese de acuerdo a éste tendría pretensión [Anspruch] de que su juicio tuviese necesidad incondicionada. $\mathrm{Si}$ carecieran de todo principio como los del mero gusto de los sentidos, no se llegaría a concebir siquiera necesidad alguna. Deben tener, por consiguiente, un principio subjetivo que determine, sólo por sentimiento y no por concepto, y sin embargo, con validez universal, lo que plazca o displazca [gefalle oder mißfalle]. Pero un tal principio sólo podría ser considerado como un sentido común [Gemeinsinn], que es esencialmente diferente del entendimiento común [gemeiner Verstand], al que a veces se llama también sentido común (sensus communis); este último, en efecto, no juzga según sentimiento, sino siempre según conceptos, si bien comúnmente sólo como principios oscuramente representados.

Así, pues, sólo bajo el supuesto de que haya un sentido común (por tal no entendemos, empero, un sentido externo, sino el efecto del libre juego de nuestras facultades de conocimiento), sólo bajo la suposición, digo, de un tal sentido común, puede ser emitido el juicio de gusto. (AA V, 237-238; CFJ 152153; CJ 168)

No se debe separar empero, tomando en cuenta estas líneas, el Gemeinsinn del sensus communis. Por el contrario, si comparamos dicho pasaje con la nota al pie del $\S 40$, podemos inferir que Kant identifica el Gemeinsinn con el sensus communis aestheticus y con el gusto, mientras que reserva para el entendimiento común humano el nombre de sensus communis logicus: «Se podría designar al gusto a través del sensus communis aestheticus, [y] al entendimiento común humano [den gemeinen Menschenverstand] a través del sensus communis logicus.» (AA V, 295.n.)

Siempre que el juicio estético haya de tener su especificidad - necesaria, a su vez, para garantizar la posibilidad del comercio entre el reino de la 
libertad y el de la naturaleza - no es posible fundarlo en principios objetivos, lo cual los transformaría en juicios de conocimiento (determinantes); tampoco es posible fundarlo, empero, en la materialidad sensible, puesto que entonces no habría universalidad ni necesidad. Sólo es posible, entonces, fundarlo en un principio subjetivo aunque común a todos los hombres. De allí que Kant recurra al sentimiento requerido para el conocimiento, en tanto que este aspira legítimamente a la universalidad. Ello se ve claramente en el §21, «Si se puede suponer con fundamento un sentido común [Gemeinsinn]»:

Conocimientos y juicios, junto con la convicción que los acompaña, tienen que poder comunicarse universalmente, pues de otro modo no tendrían concordancia [Übereinstimmung] alguna con el objeto: serían todos ellos un mero juego subjetivo de las facultades de representación, exactamente como lo quiere el escepticismo. Pero si han de poder comunicarse conocimientos, hace falta que el estado del espíritu, es decir, la disposición [Stimmung] de las facultades cognoscitivas con relación a un conocimiento en general, a saber, aquella proporción apropiada para una representación (mediante la cual un objeto nos es dado) en aras de hacer de ella conocimiento, pueda también comunicarse universalmente: porque sin ella, como condición subjetiva del conocer, no podría el conocimiento producirse como efecto. Esto ocurre también de hecho toda vez que un objeto dado por medio de los sentidos pone en actividad la imaginación para la composición de lo múltiple [Zusammensetzung des Mannigfaltigen] y ésta pone en actividad el entendimiento para la unidad [de lo múltiple] en conceptos. Pero esa disposición [Stimmung] de las facultades del conocimiento tiene, según la diversidad de los objetos dados, una diversa proporción. Sin embargo, debe haber una en la cual esa relación interna para la vivificación [Belebung] (de una por la otra) sea, en general, la más ventajosa para ambas facultades del espíritu en vista del conocimiento (de objetos dados), y esa disposición no puede ser determinada más que por el sentimiento [Gefühl] (no por conceptos). Pero como esa disposición misma tiene que poder comunicarse universalmente y, por tanto, también el sentimiento de la misma (en una representación dada), y como la comunicabilidad universal de un sentimiento presupone un sentido común [Gemeinsinn], éste podrá, pues, admitirse con fundamento, y por cierto, sin apoyarse, en ese caso, en observaciones psicológicas, sino como la condición necesaria de la comunicabilidad universal de nuestro conocimiento, la cual, en toda lógica y en todo principio del conocimiento que no sea escéptica, ha de ser presupuesta.(AA V, 238-239; CFJ 153-154; CJ 169)

El sentido común no es, pues, sólo sentido comunitario, sino también sentimiento comunitario. Ahora bien, para ello es preciso admitir el factum del que parte Kant: que hay conocimiento y que es comunicable. Estas son premisas sin las cuales el argumento no se sostiene, puesto que es sólo dado que el conocimiento debe ser comunicable que debe haber un sentimiento 
universalmente compartido relativo a la mejor disposición para él. No sólo eso, sino que también esa disposición ideal misma debe poder ser comunicada: esa es, de hecho, la razón por la cual la belleza afina el alma para el conocimiento, puesto que el juicio «esto es bello» es correlativo a un estado de la relación entre las facultades óptima para la tarea cognoscente. En ningún momento plantea Kant la duda cartesiana, acaso porque sabe que no hay respuesta que pueda hacer caer hipótesis como la del Genio Maligno. En este sentido, su punto de partida es la negación del escepticismo, y su argumentación requiere que se acepte ese punto de partida, es decir, las premisas de que (1) hay conocimiento, (2) que podemos comunicarlo, y (3) que podemos comunicar incluso nuestro estado anímico en la disposición para el conocimiento. Pero con ello, todo el sistema crítico se revela como edificado sobre el supuesto de esta disposición o afinación del alma (Stimmung) compartida universalmente.

Los supuestos mencionados requieren, a su vez, la suposición de una uniformidad empírica fuerte entre «los hombres», de modo tal que uno pueda pretender que sus juicios de experiencia y sus estados de ánimo adecuados para conocer concuerden con los de todos los demás. Esa es para Deleuze la violencia inherente al punto de vista de la representación, y expresiones filosóficas clásicas como «todo el mundo sabe» o «nadie puede negar» patentizan esta pretensión discursiva de universalidad por parte de un sujeto particular. Cuando un filósofo dice «todo el mundo sabe», está pretendiendo representar con su discurso a una totalidad conformada por una pluralidad de sujetos, los cuales, puesto que todos ellos están - supuestamente - de acuerdo en eso que el filósofo dice, constituyen un todo armónico o una comunidad concordante. En este sentido el filósofo puede ser Rey: le da a la pluralidad de sujetos un punto imaginario en el cual converger. La filosofía de Deleuze, por el contrario, es un elogio permanente de la singularidad irrepresentable:

hay alguien, aunque no sea más que uno, con la modestia necesaria, que no llega a saber lo que todo el mundo sabe, y que niega modestamente lo que se supone que todo el mundo reconoce. Alguien que no se deja representar, pero que tampoco quiere representar nada. No un particular dotado de buena voluntad y de pensamiento natural, sino un singular lleno de mala voluntad, que no llega a pensar [...]. (Deleuze, 1968, pp. 170-171)

Las nociones de minoría y devenir-menor, forjadas con Guattari en su $K a f k a$, van precisamente en este sentido. En Mil mesetas, los autores escriben:

La noción de minoría [minorité] es muy compleja, con sus remisiones musicales, literarias, lingüísticas, pero también jurídicas, políticas. Minoría y mayoría [majorité] no se oponen de una manera solamente cuantitativa. Mayoría implica 
una constante, de expresión o de contenido, como un patrón de referencia [mètreétalon] en relación al cual se evalúa. (Deleuze y Guattari, 1980, p. 133)

En este sentido, si el patrón es «Hombre-blanco-macho-adulto-citadinohablante de una lengua estándar-europeo-heterosexual cualquiera», (Ibid.) es evidente que no se trata de una mayoría cuantitativa. El punto, no obstante, es que aparece dos veces: «una vez en la constante, [y] una vez en la variable de la cual se extrae la constante». (Ibid.) Esto equivale a decir que se extrapola ilegítimamente un hecho al plano del derecho. Se trata de una estructura trascendental calcada de lo empírico: es por eso que «aparece dos veces». ${ }^{7} \mathrm{La}$ ambivalencia del vocablo francés personne con el que juegan los autores - en tanto significa tanto «alguien» como «nadie»— da plena cuenta de este pasaje, pero también de la posibilidad de realizar el pasaje en el sentido inverso:

La mayoría, en la medida en que es analíticamente comprendida en el patrón abstracto, no es nunca nadie [personne], es siempre Alguien/Nadie [Personne] - Ulises - , mientras que la minoría es el devenir de todo el mundo, su devenir potencial en tanto que se desvía del modelo. Hay un «hecho» mayoritario, pero es el hecho analítico de Alguien/Nadie, que se opone al devenir-minoritario de todo el mundo. (Deleuze y Guattari, 1980, pp. 133-134)

El hecho, la quaestio facti, es que nadie es en realidad ese modelo; por el contrario, «todo el mundo» deviene, y devenir implica por definición desviarse del modelo, con lo cual todo el mundo es siempre una minoría. Por eso, si el sentido común es correlativo al modelo o patrón «Alguien/Nadie», será preciso crear una nueva noción de la comunicación entre flujos correlativa al devenir-minoritario: el concepto deleuziano de para-sentido, en efecto, puede ser pensado como la quaestio juris del factum minoritario. Dicho concepto es acuñado por Deleuze para pensar un modo de relación entre multiplicidades no-sujetas a las identidades objetiva y subjetiva, es decir, una comunidad menor entre lo sensible, lo imaginable, lo memorable y lo pensable, sin la necesidad — por otra parte_- de permanecer «al interior» de un sujeto. ${ }^{8}$

7 Con respecto al procedimiento del calco, dice Deleuze al explicar la fórmula empirismo trascendental: «Empirismo trascendental no quiere decir nada efectivamente si no se precisan las condiciones. El 'campo' trascendental no debe ser calcado de lo empírico, como lo hace Kant: debe por su lado ser explorado en tanto tal, por ende 'experimentado' (pero [se trata] de un tipo de experiencia muy particular). Es este tipo de experiencia el que permite descubrir las multiplicidades, pero también el ejercicio del pensamiento [...].» (Deleuze, 2003, p. 339).

8 «Sin embargo, lo esencial es que, así, no reintroducimos en absoluto la forma de un sentido común, al contrario. Hemos visto cómo la discordia [discorde] de las facultades, definida por la exclusividad del objeto trascendente que cada una aprehende, no dejaba de implicar un acuerdo, según el cual cada una transmite su violencia a la otra siguiendo un cordón de pólvora, 
Con esta fusión de significados, Deleuze nos sugiere una relación indisociable entre el sentido común como concordancia entre diferentes facultades de un sujeto — pensado como Alguien/Nadie — y el sentido común como concordancia entre diferentes sujetos — relativa a una comunidad «mayor» supuestamente homogénea- En este sentido, toda teoría de las facultades es inherentemente política. Y si una teoría de las facultades gobernada por el sentido común es indisociable de una filosofía política del consenso, una teoría discordante de las facultades conlleva inherentemente una política del disenso. ${ }^{9}$

\section{SENTIDO COMÚN COMO CONSENSO}

Este veta política del sentido común es desarrollada explícitamente por Deleuze y Guattari en Mil mesetas, donde asocian el sentido común con la forma-Estado y con la facultad de las consignas (mots d'ordre).

El sentido común, la unidad de todas las facultades como centro del Cogito, es el consenso de Estado llevado al absoluto. Esa fue notoriamente la gran operación de la 'crítica' kantiana, retomada y desarrollada por el hegelianismo. Kant no ha dejado de criticar los malos usos para bendecir mejor la función. No hay que sorprenderse de que el filósofo haya devenido profesor público o funcionario de Estado. Todo está decidido desde que la forma-Estado inspira una imagen del pensamiento. (Deleuze y Guattari, 1980, p. 466)

El sentido común es aquí entendido como consenso, a la vez que se atribuye a Kant el establecimiento del mismo - de allí su importancia para la cuestión que nos ocupa. La relación con la forma-Estado debe aquí comprenderse en el sentido en que el Estado es esencialmente síntesis de la multiplicidad de los representados en la unidad del representante; pero dicha síntesis requiere

pero precisamente un 'acuerdo discordante' [accord discordant] que excluye la forma de identidad, de convergencia y de colaboración del sentido común. Ello nos parecería corresponder a la Diferencia que articula o reúne por sí misma, era esa Discordancia concordante [Discordance accordante]. Hay entonces un punto en el cual pensar, hablar, imaginar, sentir, etc., son una sola y misma cosa, pero esta cosa afirma sólo la divergencia de las facultades en su ejercicio trascendente. Se trata entonces, no de un sentido común, sino al contrario de un 'para-sentido' (en el sentido en que la paradoja es asimismo lo contrario del buen sentido). Este para-sentido tiene por elemento las Ideas, precisamente porque las Ideas son multiplicidades puras que no presuponen ninguna forma de identidad en un sentido común, sino que animan y describen al contrario el ejercicio disyunto [disjoint] de las facultades desde el punto de vista trascendente.») (Deleuze, 1968, p. 250).

9 Lawrence Quill acuña el concepto de uncommon sense para pensar los actos de desobediencia civil. «Realizar un acto de desobediencia civil en las circunstancias actuales es ejercer una forma de sentido incomún [uncommon sense].» (Quill, 2009, p. 21). 
la instauración de una unidad que presupone la existencia o la imposición de una generalidad, esto es, un patrón de medida universalmente compartido o un concepto bajo el cual caigan objetos y al que se sujeten sujetos.

La relación entre el sentido común y la forma-Estado es desarrollada con aun mayor precisión por Deleuze y Guattari en la hipótesis de que la doctrina concordante de las facultades de acuerdo con el sentido común tiene su origen en la relación entre los órganos de poder del Estado. «Desde que la filosofía se asignó el rol de fundamento, no ha dejado de bendecir los poderes establecidos, y de calcar su doctrina de las facultades de los órganos de poder del Estado.» (Ibid.) De este modo, la concordia facultatum pasa de tener un fundamento moral en Diferencia y repetición a tener un fundamento político en Mil mesetas. Se produce en la Modernidad una alianza entre pensamiento y Estado, según la cual «[e]l Estado le da al pensamiento una forma de interioridad, pero el pensamiento le da a esta interioridad una forma de universalidad». (Deleuze y Guattari, 1980, p. 465) El paralelismo entre facultades y órganos resulta en sumo grado sugerente, especialmente si lo ponemos en relación con la crítica que Deleuze y Guattari dirigen al organismo y al Estado en tanto que orgánico. De este modo, si los autores contraponen al organismo un Cuerpo sin Órganos (CsO), podemos, siguiendo dicho paralelismo, contraponer al Yo o al alma orgánica un Alma sin Facultades (AsF). Así como en el CsO se trata de la destrucción no de los órganos sino de la organización de los mismos en un organismo, se trataría en el AsF de la destrucción no de las facultades, sino de su ejercicio concordante subordinado al sentido común. ${ }^{10}$ Implicaría, por lo tanto, un uso libre y discordante de las facultades, en el cual estas no se vean compelidas a converger en un objeto ideal trascendente, pero que tampoco presuponga un patrón mayoritario como el sensus communis de la tercera Crítica. Se trataría, aun, de una descodificación de las facultades como flujos, antes codificadas por el sentido común.

10 Si bien Deleuze decía en Lógica del sentido que el sentido común debe entenderse en el sentido de un órgano, tomando como base la terminología de Capitalisme et schizophrénie habría que decir que el sentido común es más bien el organismo espiritual. «En el 'sentido común', 'sentido' no se dice ya de una dirección, sino de un órgano. Se lo llama común porque es un órgano, una función, una facultad de identificación, que remite una diversidad cualquiera a la forma de lo Mismo. El sentido común identifica, reconoce, así como el buen sentido prevé. Subjetivamente, el sentido común subsume facultades diversas del alma u órganos diferenciados del cuerpo, y los remite a una unidad capaz de decir Yo [Moi]: es un sólo y mismo yo [moi] el que percibe, imagina, recuerda, sabe, etc.; y el que respira, que duerme, que camina, que come...» (Deleuze, 1969, p. 95). 
En una muy reveladora nota al pie de Mil mesetas, Deleuze y Guattari señalan:

Toda la teoría racionalista clásica de un 'sentido común', de un buen sentido universalmente repartido, fundado en la información y la comunicación, es una manera de recubrir o de esconder, y de justificar de antemano, una facultad mucho más inquietante que es la de las consignas [mots d'ordre]. Facultad singularmente irracional que se avala tanto más en cuanto que se la bendice en nombre de la razón pura, nada más que la razón pura... (Deleuze y Guattari, 1980, p. 108)

Lo que están allí criticando los autores es la idea de autonomía del sujeto. El efecto, para Deleuze y Guattari, del discurso de la autonomía o de la identidad entre sujeto y legislador no es la emancipación sino, por el contrario, la sujeción (assujettissement), puesto que cuanto más nos creemos libres y autodeterminados - siendo en realidad composiciones cambiantes de fuerzas y afectos irreductibles a cualquier supuesta identidad subjetiva-, tanto más nos ajustamos al patrón mayoritario impuesto por los poderes. «Obedezcan siempre, ya que, cuando más obedezcan, más serán amos, puesto que no obedecerán sino a la razón pura, es decir a ustedes mismos...» (Deleuze y Guattari 1980, p. 466)

En este libro, la contraposición ya no se da - como en Diferencia y repetición - entre el modelo del reconocimiento y un pensamiento sin imagen, sino entre un plano de organización y un plano de inmanencia o consistencia. Ello implica que la imagen del pensamiento deja de ser tratada como una ilusión para pasar a ser un actor en la constitución de lo real. Este carácter ya estaba presente en el libro de 1968, pero en tanto que la imagen del pensamiento era señalada como elemento genético no de lo real sino de la representación, podía ser pensada en términos ilusorios, algo que Deleuze y Guattari intentarán evitar-principalmente, en su combate contra el concepto de ideología. (Cf. Deleuze 1968, pp. 49-52, 341) La representación como ilusión trascendental en Diferencia y repetición, en efecto, reviste las características principales del concepto marxiano de ideología. Deleuze habla allí del «cuádruple yugo de la representación» que somete la diferencia a la identidad como una ilusión trascendental, cuyas cuatro formas corresponden, respectivamente, al ser (analogía en el juicio), al pensamiento (identidad), a lo sensible (semejanza en la percepción), y a las Ideas-problema (oposición en los predicados en tanto espejismo de lo negativo, producida como sombra de las positividad de los problemas proyectada sobre las soluciones posibles).

Existen, por lo demás, varias maneras en que se puede pensar el sentido común en las obras escritas por Deleuze junto a Guattari. Vimos ya que el concepto de mayoría estaba estrechamente relacionado con el sentido común; sin embargo, también es posible pensar los conceptos de estrato y de molaridad 
en esta misma línea. Si aceptamos esta afinidad conceptual, es preciso señalar que en los textos posteriores a El Anti-Edipo Deleuze y Guattari subrayarán la necesidad de guardar un poco de sentido común. Este énfasis en la prudencia se ve especialmente en Mil mesetas, donde el problema es planteado en términos de evitar que una línea de fuga se convierta en línea de abolición o línea de muerte. Los autores presentan allí tres estratos: el organismo, la significancia y la subjetivación.

Serás organizado, serás un organismo, articularás tu cuerpo - si no, serás un depravado. Serás significante y significado, intérprete e interpretado - si no, serás un desviado. Serás sujeto, y fijado como tal, sujeto de enunciación doblegado en un sujeto de enunciado- si no, serás un vagabundo. (Deleuze y Guattari, 1980, p. 197)

A los tres estratos, Deleuze y Guattari contraponen tres operaciones: desarticulación (del organismo), experimentación (en vez de significación) y nomadismo (de la subjetividad). En este sentido, todo movimiento creativo implica una huida del sentido común o una desestratificación; pero al mismo tiempo, es necesario conservar siempre un poco de estrato o de sentido común para no enmudecer (significancia), para no enloquecer (subjetividad) y, sobre todo, para no morir (organismo).

Del organismo, hay que guardar suficiente como para que se reforme a cada alba; y hay que guardar pequeñas provisiones de significancia y de interpretación, aunque más no sea para oponerlas a su propio sistema cuando las circunstancias lo exijan, cuando las cosas, las personas, incluso las situaciones os fuercen a ello; y hay que guardar pequeñas raciones de subjetividad, suficientes como para poder responder a la realidad dominante. (Deleuze y Guattari, 1980, p. 198)

La lucidez de esta concepción de la prudencia agrega un componente importante a la propuesta rupturista respecto del sentido común. En la misma línea va la siguiente advertencia de Deleuze: «No basta con fugar para producir un nómade, no basta dejar de interpretar para devenir un experimentador, y sobre todo no basta con desorganizar el organismo para devenir un cuerpo sin órganos con cosas que pasen sobre él. Cada vez esto puede ser la muerte.» (Deleuze, 1974, p. 216) Y aun sin llegar a la muerte, Deleuze nos advierte sobre las formaciones de angustia que emergen al deshacer los dispositivos que nos sujetan: «Hay toda suerte de formaciones de angustia que corresponden a la defección de los estratos.» (Ibid., p. 217)

En los sentidos hasta aquí desarrollados puede verse que, al contrario de lo que el propio sentido común piensa de sí mismo, este reviste esencialmente una dimensión normativa y prescriptiva. Esta dimensión, asimismo, remite necesariamente a una comunidad de sentido o a un universo de sentido 
compartido por una comunidad supuesta. El mandato o imperativo impuesto por el sentido común es el de no romper con ese universo de sentido común a ese todos que no es nadie. La consigna de concordancia propia del sentido común, ya sea con respecto a las facultades, al cuerpo, o la comunidad, implica una sujeción de los flujos a un modelo mayoritario que se adecúa a los requisitos de los poderes. Será preciso encontrar entonces líneas de fuga al sentido común, aunque siempre con prudencia.

\section{A MODO DE CONCLUSIÓN}

La propuesta deleuziana para evitar los peligros del sentido común y establecer no obstante vínculos entre lo real consiste, como vimos, en la idea de un para-sentido, esto es, de un acuerdo discordante paradójicamente inspirado por el mismo libro del cual Deleuze toma el concepto de sentido común, viz., la tercera Crítica kantiana. No es el objetivo del presente trabajo desarrollar dicha noción. Nos propusimos, en cambio, subrayar los mentados peligros. En cuanto a estos, subrayamos en primer lugar la tendencia intrínseca al sentido común a la apelación a la autoridad y los lugares comunes aceptados, es decir, a lo ya reconocido. Nos detuvimos, no obstante, en una transición operada a este respecto en el corpus deleuziano: mientras que en Diferencia y repetición la crítica al sentido común era efectuada desde el punto de vista de una revisión de lo que significa pensar, y en este sentido, aquél era denunciado como la doxa mantenida en el corazón de la filosofía, en los estudios sobre cine el sentido común se transforma en clichés, que ya no conciernen exclusiva ni específicamente a la filosofía sino que son pensados como los signos materiales que nos constituyen física y psíquicamente.

En segundo lugar, fue preciso analizar algunos pasajes de la Crítica de la facultad de juzgar con el fin de poner de relieve, a partir de la letra kantiana, que el sentido y el sentimiento comunitario correlativos a la noción de sensus communis implica un modelo homogéneo para todos los hombres que podemos acercar al concepto deleuzo-guattariano de lo mayoritario, en tanto patrón de medida que se supone universal pero que no se corresponde con los devenires efectivos dados en la experiencia; de allí su dimensión esencialmente normativa y prescriptiva.

Por último, señalamos la mutación del concepto de sentido común en Deleuze desde nuestro punto de partida, Diferencia y repetición, hasta Mil mesetas, donde le era atribuido un origen no ya moral sino político basado en el consenso en la relación entre los órganos del Estado moderno. En este último libro, al igual que en los estudios sobre cine, el sentido común se desligaba del ámbito noético para adquirir una dimensión orgánica, semiótica y subjetivante. Al mismo tiempo, hicimos hincapié en el rol de la prudencia 
previamente ausente, el cual acaso deba atribuirse a consecuencias indeseadas del anti-Edipo en algunos de sus lectores. ${ }^{11}$

Antes de finalizar, tenemos que hacer frente a tres objeciones posibles. La primera de ellas plantearía que el sentido común es lo más democrático e igualitario. Así, cuando Descartes rechaza las nociones escolásticas para definir al hombre, apela a la luz natural presente en todos nosotros sin distinción entre legos y doctos. Más allá de las buenas intenciones, el problema con esta posición, para Deleuze, es que presupone que de hecho tenemos buenas intenciones y que esa luz natural no reviste una dimensión normativa. Se trata en ambos casos de presupuestos infundados, o más bien, fundados en la imagen dogmática del pensamiento. Deleuze es más cercano, en este punto, a la Realpolitik característica del Kant tardío - e.g. Zum ewigen Frieden-, que creía en la necesidad de pensar una política que funcionara inclusive en «un pueblo de demonios.» (AA VIII, 366) No parece prudente dar por sentado nuestra propia buena voluntad como pensadores, más aun teniendo en cuenta los efectos de poder generados por esta autoevaluación conjugada con una pretensión de universalidad.

La segunda objeción plantearía que dejar de lado el sentido comunitario equivaldría a resguardarse en el individuo-átomo, como si el peligro fuese que los brillantes raciocinios de un sujeto autónomo se dejaran contaminar por sentidos vulgares. Sin embargo, ya el propio Kant distinguía en la Antropología entre sensus communis y sensus vulgaris: el concepto de sentido común no tiene una relación necesaria con el de vulgo. (Cf. AA VII, 139) Por otra parte, el problema no es la presencia de la alteridad en nosotros; dicha presencia es constitutiva e inevitable. En una ontología no-identitaria como la de Deleuze(Guattari), de lo que se trata es de visibilizar, evaluar y politizar los modos de esta presencia. El sentido común, al contrario, pretende invisibilizar su propia alteridad y su propia contingencia.

La tercera objeción posible, íntimamente ligada con la segunda, es que sólo se puede escapar al sentido común en privado, es decir, que, siguiendo la propuesta deleuziana, sería imposible la construcción colectiva. Sin embargo, al igual que una Idea-problema pasa por distintas facultades, despertándolas y al mismo tiempo transformándose en cada caso, del mismo modo los problemas atraviesan distintos individuos, cambiándolos y cambiando ellos mismos en el proceso. De hecho, puesto que el sujeto es para Deleuze un límite impuesto arbitrariamente a ciertos flujos de lo real, la producción es siempre

11 Dicho libro fue interpretado, especialmente entre algunos jóvenes estudiantes de Vincennes, como una vindicación de la esquizofrenia y la experimentación con las drogas. Al respecto, $c f$. Dosse, 2007, pp. 261-281. 
necesariamente colectiva, ya que se da en un nivel previo a la repartición sedentaria de sujetos en un orden metafísico-jurídico.

\section{REFERENCIAS BIBLIOGRÁFICAS}

ALLISON, H. 1992 (1983): El idealismo trascendental de Kant: una interpretación y defensa. Trad. Dulce María Granja Castro. Barcelona: Ánthropos.

ARENDT, H. 1971: «Thinking and Moral Considerations: A Lecture», Social Research, 38:3, pp. 416-446.

ARENDT, H. 1992: Lectures on Kant's Political Philosophy. Chicago: The University of Chicago Press.

ARISTÓTELES 1982: Tratados de lógica (Órganon). Categorías - Tópicos - Las refutaciones sofisticas. Trad. Miguel Candel Sanmartín, Madrid: Gredos.

BARTHES, R. 1982: Investigaciones retóricas I. La antigua retórica. Ayudamemoria. Buenos Aires: Ediciones Buenos Aires.

DELEUZE, G. 1983: Cinéma 1. L'Image-Mouvement. París: Minuit.

DELEUZE, G. 1985: Cinéma 2. L'Image-Temps. París: Minuit.

DELEUZE, G. 2010 (1974): Derrames. Entre el capitalismo y la esquizofrenia. Trad. Equipo Editorial Cactus. Buenos Aires: Cactus.

DELEUZE, G. 1968: Différence et répétition. París: PUF.

DELEUZE, G. 2003: Deux régimes de fous. Textes et entretiens (1975-1995). París: Minuit.

DELEUZE, G. 1969: Logique du sens. París: Minuit.

DELEUZE, G. y GUATTARI, F. 1980 : Capitalisme et schizophrénie II. Mille plateaux. Paris: Minuit.

DOSSE, F. 2009 (2007): Gilles Deleuze y Félix Guattari. Biografías cruzadas. Trad. Sandra Garzonio. Buenos Aires: Fondo de Cultura Económica.

FERREYRA, J. 2016: «Deleuze's Bêtise: Dissolution and Genesis in the Properly Human Form of Bestiality», Comparative and Continental Philosophy, 8, pp. 26-36.

HÖLDERLIN, F. 1953 (1808): Sämtliche Werke. 6 Bände. Band 2. Stuttgart: J. G. Cotta.

KANT, I. 1991 (1790): Crítica de la facultad de juzgar. Trad. Pablo Oyarzún. Caracas: Monte Ávila.

KANT, I. 2007 (1790): Crítica del Juicio. Trad. Manuel García Morente. Madrid: Espasa Calpe.

KANT, I. 1900 ss. (1790): Kants gesammelte Schriften. Abteilung 1: Werke: Band V: Kritik der praktischen Vernunft, Kritik der Urteilskraft. Berlín: Königlich Preußischen Akademie der Wissenschaften. 
QUILL, L. 2009: Civil Disobedience. (Un)Common Sense in Mass Democracies, New York: Palgrave Macmillan.

PABlo Nicolás Pachilla es becario posdoctoral el CONICET e investigador visitante en la Freie Universität Berlin.

Lineas de Investigación:

Filosofía continental del XX, Filosofías de la naturaleza, Idealismo

Publicaciones recientes:

2019: «Sentido común y buen sentido en Deleuze». Valenciana. Estudios de filosofía y letras 23: 139-174.

2018: «Deleuze y la inversión del kantismo». Areté. Revista de Filosofía 30: 147-162.

Correo electrónico: pablopachilla@gmail.com 